\title{
Computer-assisted instruction before colonoscopy is as effective as nurse counselling, a clinical pilot trial
}

\section{다(1) $(9$}

\begin{abstract}
Authors
Institutions

1 Department of Gastroenterology and Hepatology, Radboud University Medical Centre, Nijmegen, The Netherlands

2 Department of Gastroenterology and Hepatology, Medical Centre Alkmaar, Alkmaar, The Netherlands
\end{abstract}

Govert Veldhuijzen ${ }^{1}$, Michael Klemt-Kropp ${ }^{2}$, Casper Noomen ${ }^{2}$, Aura A. Van Esch ${ }^{1}$, Eric T. Tjwa ${ }^{1}$, Joost Drenth ${ }^{1}$ of clean colons and improves patient experience. submitted 25.10.2016

accepted after revision $\quad 2.3 .2017$

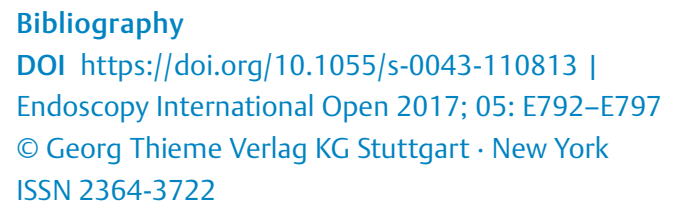

Corresponding author

Govert Veldhuijzen, Department of Gastroenterology and Hepatology, Radboud University Medical Centre, Geert Grooteplein 8, Nijmegen $6500 \mathrm{HB}$, the Netherlands Fax: +31243635129

Govert.Veldhuijzen@radboudumc.nl

\section{ABSTRACT}

Background and study aims Better patient education prior to colonoscopy improves adherence to instructions for bowel preparation and leads to cleaner colons. We reasoned that computer assisted instruction (CAI) using video and $3 \mathrm{D}$ animations followed by nurse contact maximizes the effectiveness of nurse counselling, increases proportion

Patients and methods Adults referred for colonoscopy in a high-volume endoscopy unit in the Netherlands were included. Exclusion criteria were illiteracy in Dutch and audiovisual handicaps. Patients were prospectively divided into 2 groups, 1 group received nurse counselling and 1 group received CAl and a nurse contact before colonoscopy. The main outcome, cleanliness of the colon during examination, was measured with Ottawa Bowel Preparation Scale (OBPS) and Boston Bowel Preparation Scale (BBPS). We assessed patient comfort and anxiety at 3 different time points.

Results We included 385 patients: 197 received traditional nurse counselling and 188 received CAI. Overall patient response rates were $99 \%, 76.4 \%$ and $69.9 \%$ respectively. Endoscopists scored cleanliness in $60.8 \%$. Comparative analysis of the $39.2 \%$ of patients with missing scores showed no significant difference on age, gender or educational level. Baseline characteristics were evenly distributed over the groups. Bowel cleanliness was satisfactory and did not differ amongst groups: nurse vs. CAl group scores in BBPS: (6.54 \pm 1.69 vs. $6.42 \pm 1.62)$; OBPS: $(6.07 \pm 2.53$ vs. $5.80 \pm$ 2.90). Patient comfort scores were significantly higher $(4.29 \pm 0.62$ vs. $4.42 \pm 0.68)$ in the CAl group shortly before colonoscopy. Anxiety and knowledge scores were similar.

Conclusion CAI is a safe and practical tool to instruct patients before colonoscopy. We recommend the combination of CAI with a short nurse contact for daily practice.

\section{Introduction}

Colonoscopy is the gold standard for diagnosis, surveillance and removal of precancerous lesions like adenoma in the colon, which reduces colorectal cancer mortality [1]. The importance herein is well advocated [2]. On the other hand, the prospect of undergoing colonoscopy and the intensive preparation might have a negative effect on patient comfort and anxiety [3].

Adequate bowel preparation is crucial, so it is paramount to optimally inform and instruct our patients prior to a colonoscopy [4]. Poorly prepared colons lead to a higher miss-rate of neo- plasms,[5] more complications and increased need for repeat examinations with increased costs and cumulative discomfort for patients [6, 7]. Therefore, to achieve adequate bowel cleanliness, patients have to adhere to prescribed use of laxative agents and dietary instructions [8]. Patient cleansing scores are influenced by ASA status, comorbidity, and treatment with gut motility modifying drugs. In our study, where these factors were unaffected by the intervention, we did not evaluate these further.

Patient education is obviously of key importance in achieving a well-prepared colon. Several educational tools are known 
to be effective in various degrees; e. g. informative leaflets, cartoons, video and dedicated counselling sessions by a nurse or a physician [3,9-13]. Better education overall establishes higher quality of bowel preparation [14]. In the Netherlands the most common strategy is to provide nurse counseling prior to endoscopy.

In recent years, advances in internet technology provide us with novel, web-based education programs, enabling us to combine the previously mentioned modalities. Computer-assisted instruction (CAI), available on desktop and smartphone, helps to raise patient satisfaction about the information provided [15]. Proper implementation, however, is important [16].

The evidence base that supports use of CAI for bowel preparation is lacking. We hypothesise that $C A$ I using video and $3 D$ animations maximizes effectiveness of nurse counselling and therefore improves bowel cleanliness. Furthermore, CAI will positively influence the patient experience.

We conducted a pilot trial assessing the effectiveness of CAI for patient education prior to colonoscopy measuring bowel cleanliness and patient comfort and anxiety.

\section{Patients and methods}

We used a prospective, single center, endoscopist-blinded, controlled design to conduct our pilot study.

\section{Patients}

Consecutive patients older than 18 years referred for elective colonoscopy were included from March 2013 until November 2013 in a single, large-volume endoscopy center (over 4000 colonoscopies/year) in the upper Amsterdam Area in the Netherlands. Exclusion criteria were illiteracy in Dutch and significant audiovisual/mental handicaps. Patients were prescribed the same split-dose preparation regimen of picosulfate sodium and low-fiber dietary advice in the days preceding the colonoscopy.

\section{Study design}

After informed consent was obtained, patients were divided in 2 groups: the control group received nurse counselling and the intervention group received CAI. We administered 3 patientquestionnaires at 3 time points (See the flowchart in $>$ Fig. 1.)

In the first questionnaire, patients reported their baseline characteristics regarding age, gender, educational level, ethnicity, use of drugs, number of recent physician visits and experience in multimedia and Internet access. Patients rated comfort ("How do you feel after the received information?") and anxiety ("How anxious are you") on a 5-point Likert scale (T1). Subsequently the CAl group had contact with a trained endoscopy nurse for practical matters like bridging in anticoagulant therapy, insulin dosage calculation and scheduling of the colonoscopy. In addition, we also provided a unique hyperlink to the CAI with unlimited access. Next, patients were scheduled for colonoscopy, maximum 6 weeks after the counselling session.

After check-in at the endoscopy unit in the hour prior to colonoscopy, patients rated comfort and anxiety. Additionally patient knowledge and comprehension of the provided counsel-

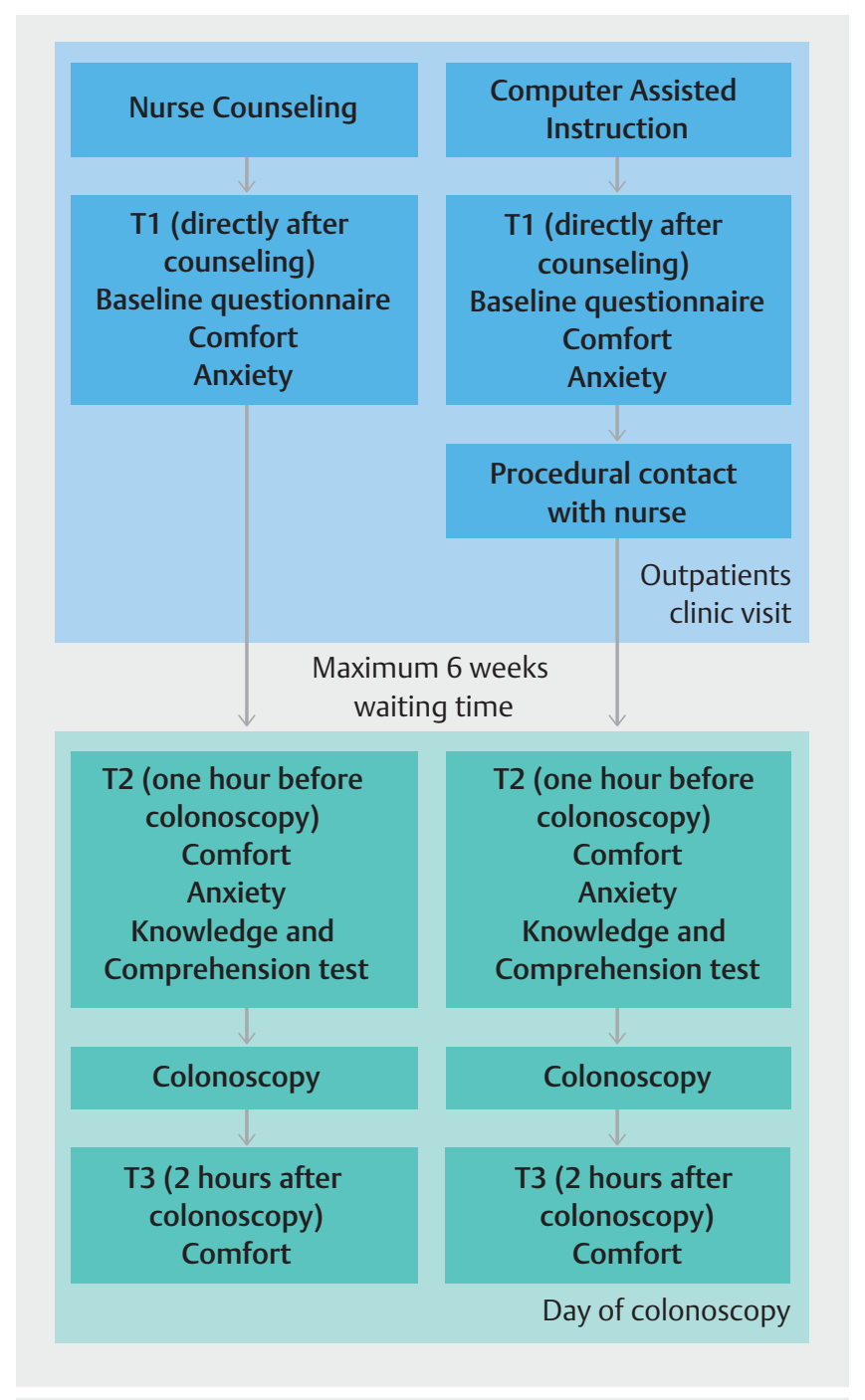

Fig. 1 Flowchart

ling information were tested in a 10-question survey (T2). Within 2 hours post-colonoscopy, patient comfort was again scored on the 5-point Likert scale (T3).

During colonoscopy, the endoscopist assessed bowel cleanliness with the Boston Bowel Preparation Scale (BBPS); a cumulative score of 3 bowel segments, ranging from $0-1$ "unsatisfactory", 2-3 “poor", 4-5 "fair", 6-7 "good”, 8-9 "excellent" [17]. To detect subtle differences we applied the Ottawa Bowel Preparation Scale (OBPS). This scale is based on the combination of cumulative scores of 3 bowel segments ( 0 "excellent", 1 "good", 2 "fair", 3 "poor", 4 "inadequate"), with added points for the amount of residual fluid ( 0 "none", 1 "moderate" and 2 “large") [18].

\section{Computer-assisted instruction}

We designed interactive $\mathrm{CAl}$, according to current best practices, such as good accessibility, plain language and a presentation that engaged the user [19]. We presented the information in a stepwise fashion. CAl consists of a web-based platform using video to mimic the patient journey with a voiceover sup- 

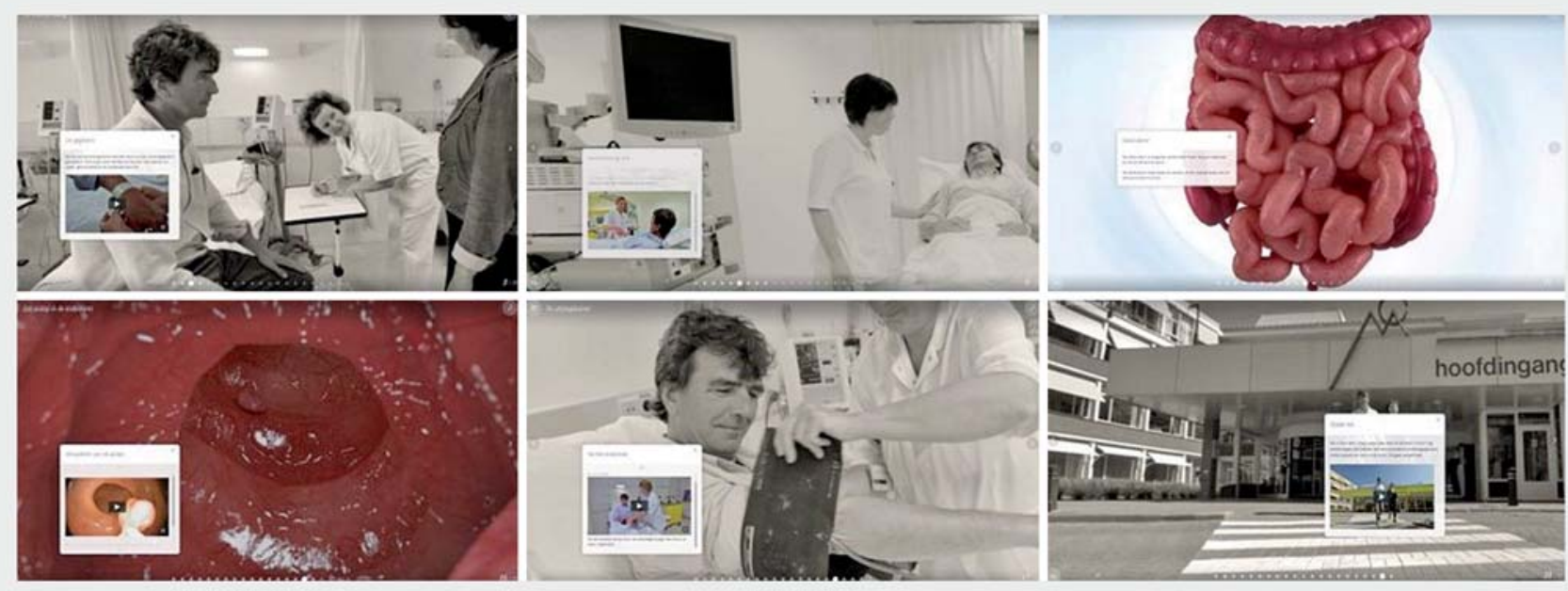

Fig. 2 Several screenshots from the computer-assisted instruction (the people in these stills are actors).

ported by photo's, $3 \mathrm{D}$ animation and instructive texts ( $\mathbf{F i g . 2}$, CAI is available in Dutch via https://trials.medify.eu/cai-colonoscopy). The video was presented in short clips, maximum of 45 seconds, to maintain patient focus. Patient interaction was ascertained by a mandatory mouse-click after each item in the CAI.

All informative elements, especially mandatory for informed consent for colonoscopy (risks, alternatives) were included.

\section{Outcomes}

The primary outcome was cleanliness of the colon during examination as assessed by the OBPS and the BBPS. The secondary outcomes were patient comfort with the received information, anxiety and knowledge and comprehension.

\section{Statistical analyses}

A sample size of 322 provides $80 \%$ power, with a 2-tailed $\alpha$ of 0.05 , to detect an increase in the primary outcome measure (BBPS) from 6.0 in the control group to 6.5 in the experimental group, with a standard deviation of 1.6.

All analyses were performed using SPSS version 20.0 for Windows (SPSS Inc., Chicago, IL, USA). We used descriptive statistics to describe baseline information including frequency count, percentage and mean \pm standard deviation. Further analyses included the chi-square test, independent t-test and Mann-Whitney. P-values under 0.05 were regarded statistically significant.

\section{Registration number}

The trial was registered in ClinicalTrials.gov with number: NCT02656602

\section{Ethical considerations}

The study was approved by the institutional review board of the Medical Center Alkmaar.

\section{Results}

\section{Patients}

We included 385 patients, 197 in the nurse counselling group and 188 in the CAI group. Baseline characteristics regarding age, gender, educational level and ethnicity were equally distributed among both groups. Mean age was 57 years (range $18-83$ ) in the nurse counselling group versus 59 years (range 18 -89) in the CAl group. Educational levels were representative to the general Dutch population [20]. The majority of the participants were of Dutch ethnicity ( $87 \%$ ) ( Table 1 ).

Both groups were also similar in the number of drugs used and recent physician visits. Use of email was comparably high, over $90 \%$ in both groups $(90.9 \%$ versus $94.1 \%$ in the CAI group).

Overall scoring rate of data collection queries at the chosen time points was $99 \%$ at $\mathrm{T} 1,76.4 \%$ at T2 and $69.9 \%$ at T3.Patients who did not score at $\mathrm{T} 1, \mathrm{~T} 2$ or $\mathrm{T} 3$ were not included in the time point analysis.

The bowel preparation regimen prescribed was picosulfate sodium (99\%), in split dose. For clinical reasons, 2 patients received polyethylene glycol, sodium sulphate, sodium bicarbonate, sodium chloride, potassium chloride.

\section{Primary outcome}

Bowel cleanliness was equal in the 2 groups with mean total BBPS scores of $6.54( \pm 1.69)$ in the nurse counselling group and $6.42( \pm 1.62)$ in the CAl group. This is "good" according to the scale [17].

According to OBPS the nurse counselling group scored 6.07 $( \pm 2.53)$ and the CAl group $5.80( \pm 2.90)$. Here, the score is "good-fair" ( Table 2) [18]. Both scales were scored in $60.8 \%$ of all cases. Comparative analysis of the $39.2 \%$ of patients with missing scores showed no significant difference on age, gender or educational level. 
- Table 1 Baseline Characteristics.

\begin{tabular}{|c|c|c|c|}
\hline & Nurse counseling & Computer Assisted Instruction & Nurse versus Computer Assisted Instruction (statistical test) \\
\hline \multicolumn{4}{|l|}{ Gender ( $\mathrm{n}, \%)$} \\
\hline - Male & $97(49.2)$ & $90(47.9)$ & $p=0.789$ \\
\hline - Female & $100(50.8)$ & $98(52.1)$ & (Chi-Square) \\
\hline Age (mean, range) & 57 years, $18-83$ & 59 years, $18-89$ & $\begin{array}{l}\mathrm{p}=0.09619 \\
\text { (t-test) }\end{array}$ \\
\hline \multicolumn{4}{|l|}{ Ethnicity (n, \%) } \\
\hline - Native Dutch & $177(89.8)$ & $163(86.7)$ & $P=0.384$ \\
\hline - Other & $20(10.2)$ & $25(13.3)$ & (Chi-Square) \\
\hline \multicolumn{4}{|c|}{ Educational level ${ }^{1}(\mathrm{n}, \%)$} \\
\hline . Low & $59(29.9)$ & $43(22.9)$ & \multirow{3}{*}{$\begin{array}{l}P=0.131 \\
\text { (Mann-Whitney) }\end{array}$} \\
\hline - Middle & $68(34.5$ & $68(36.2)$ & \\
\hline - High & $70(35.5)$ & $77(41.0)$ & \\
\hline
\end{tabular}

- Table 2 Primary outcome: Bowel Cleanliness during colonoscopy.

\begin{tabular}{|l|l|l|l|}
\hline & $\begin{array}{l}\text { Nurse counseling } \\
\text { (n, \% scoring rate) }\end{array}$ & $\begin{array}{l}\text { Computer-assisted instruction } \\
\text { (n, \% scoring rate) }\end{array}$ & $\begin{array}{l}\text { Nurse versus computer-assisted instruction } \\
\text { (Mann-Whitney) }\end{array}$ \\
\hline $\begin{array}{l}\text { Ottawa Bowel Preparation Scale } \\
\text { (mean, SD) }\end{array}$ & $\begin{array}{l}6.07, \pm 2.53 \\
(n=115,58.4 \%)\end{array}$ & $\begin{array}{l}5.80, \pm 2.90 \\
(n=87,46.3 \%)\end{array}$ & $P=\mathbf{0 . 4 1 8}$ \\
\hline $\begin{array}{l}\text { Boston Bowel Preparation Scale } \\
\text { (mean, SD) }\end{array}$ & $\begin{array}{l}6.54, \pm 1.69 \\
(n=129,65.5 \%)\end{array}$ & $\begin{array}{l}6.42, \pm 1.62 \\
(n=88,46.8 \%)\end{array}$ & $P=\mathbf{0 . 5 7 6}$ \\
\hline
\end{tabular}

\section{Secondary outcomes}

\section{Comfort with the received information}

Patient comfort scores directly after counselling (T1) were 4.54 \pm 0.56 in the nurse counselling group and $4.17 \pm 0.51$ in the CAI group ( $p<0.0001$ ). Patient comfort scores prior to colonoscopy (T2) were significantly higher in the CAl group compared to the nurse counselling group $(4.42 \pm 0.68$ vs $4.29 \pm 0.62, P=0.039)$. Patient comfort scores after colonoscopy (T3) were not different between groups ( $\triangleright$ Table $\mathbf{3}$ ).

Anxiety

We found no significant differences between groups in the 5point Likert anxiety scores at T1 (total mean $3.04 \pm 1.27$ ) and T2 (total mean $2.84 \pm 1.30$ ) ( $\triangleright$ Table 3 ).

\section{Knowledge and comprehension}

The scores for the 10-question survey did not differ between groups $(7.31 \pm 1.11$ vs $7.08 \pm 1.17, P=0.12)$ ( $\vee$ Table 3 ).

\section{Discussion}

The current study shows that CAI before colonoscopy results in well-prepared colons, comparable to face-to-face nurse coun- selling. We found that patients who were informed through CAI achieved higher grades of comfort. Interestingly, at baseline this rating was higher for the nurse counselling group, suggesting the influence of the human factor.

Current research on patient education in colonoscopy has been focused on use of leaflets, video, phone intervention and nurse or physician counselling sessions [3,9-13]. In this era of information technology with Internet, social media and open access sources, computers are anchored in the seeking and gathering behavior by patients for medical instructions as it is fast, easy to use and ubiquitously accessible. The threat is that the information may be experienced as incomprehensible, insufficient and even incorrect. CAl, as provided by the endoscopy unit, has the potential to combine the upsides of the above tools without drawbacks such as passive learning [21].

CAl empowers the patient in place, pace and moment of learning, known to have impact on patients satisfaction [22]. In addition, reviewing and sharing online information with relatives is comfortably facilitated. In our trial, some patients viewed the CAl up to 6 or 7 times after being provided the secured unique patient hyperlink (data not shown). It is tempting to believe that this contributes to higher grades of comfort before colonoscopy using CAl. 
- Table 3 Secondary outcomes: Comfort, anxiety and knowledge and comprehension

\begin{tabular}{|c|c|c|c|}
\hline & $\begin{array}{l}\text { Nurse counseling } \\
\text { (n, \% scoring rate) }\end{array}$ & $\begin{array}{l}\text { Computer-assisted instruction } \\
\text { (n, \% scoring rate) }\end{array}$ & $\begin{array}{l}\text { Nurse versus computer-assisted } \\
\text { instruction (Mann-Whitney) }\end{array}$ \\
\hline $\begin{array}{l}\text { Comfort score after consult/CAI (T1) } \\
\text { ( } 1=\text { very low, } 5=\text { very high })\end{array}$ & $\begin{array}{l}\text { Mean } 4.54, \pm 0.56 \\
(n=193,98.0 \%)\end{array}$ & $\begin{array}{l}\text { Mean } 4.17, \pm 0.51 \\
(n=188,100 \%)\end{array}$ & $P=0.000$ \\
\hline $\begin{array}{l}\text { Comfort score before endoscopy (T2) } \\
\text { ( } 1 \text { = very low, } 5 \text { = very high) }\end{array}$ & $\begin{array}{l}\text { Mean } 4.29, \pm 0.62 \\
(n=162,82.2 \%)\end{array}$ & $\begin{array}{l}\text { Mean } 4.42, \pm 0.68 \\
(n=124,66.0 \%)\end{array}$ & $P=0.039$ \\
\hline $\begin{array}{l}\text { Comfort score after endoscopy (T3) } \\
\text { ( } 1 \text { = very low, } 5 \text { = very high) }\end{array}$ & $\begin{array}{l}\text { Mean } 4.16, \pm 0.93 \\
(n=150,76.1 \%)\end{array}$ & $\begin{array}{l}\text { Mean } 4.28, \pm 0.84 \\
(n=117,62.2 \%)\end{array}$ & $P=0.322$ \\
\hline $\begin{array}{l}\text { Anxiety score after consult/CAI (T1) } \\
\text { ( } 5 \text { = very low, } 1=\text { very high) }\end{array}$ & $\begin{array}{l}\text { Mean } 3.16, \pm 1.30 \\
(n=193,98.0 \%)\end{array}$ & $\begin{array}{l}\text { Mean } 2.92, \pm 1.22 \\
(n=188,100 \%)\end{array}$ & $P=0.071$ \\
\hline $\begin{array}{l}\text { Anxiety score before endoscopy (T2) } \\
\text { ( } 5=\text { very low, } 1=\text { very high) }\end{array}$ & $\begin{array}{l}\text { Mean } 2.80, \pm 1.32 \\
(n=162,82.2 \%)\end{array}$ & $\begin{array}{l}\text { Mean } 2.90, \pm 1.27 \\
(n=124,66.0 \%)\end{array}$ & $P=0.451$ \\
\hline $\begin{array}{l}\text { Knowledge and comprehension } 10 \text {-item } \\
\text { test score before endoscopy }\end{array}$ & $\begin{array}{l}\text { Mean } 7.08, \pm 1.17 \\
(n=164,83.2 \%)\end{array}$ & $\begin{array}{l}\text { Mean } 7.31, \pm 1.11 \\
(n=127,67.6 \%)\end{array}$ & $P=\mathbf{0 . 1 1 2}$ \\
\hline
\end{tabular}

Familiarity with use of computers, notably among elderly patients, could be of concern. In our cohort, $40 \%$ in the CAI group were older than 65 years. We did not find an age-dependent effect (data not shown). However, before drawing general conclusions from our results, we need to confirm this in larger studies.

Nurse counseling certainly provides personal contact and offers emotional support. Indeed, we observed higher comfort scores immediately after nurse counselling compared to CAI. On the other hand, limitations of this human factor in transferring information include distraction from the content, nuisances in the interpersonal domain and the non-uniformity by definition when different nurses or physicians are involved.

\section{Limitations}

A limitation of the current study is its non-randomized design. This was due to the unavailability of the CAl at the start of patient inclusion. However, this design did not affect the scoring by endoscopists as they were unaware of this information and therefore unaware of assignment over the groups while assessing the primary endpoint. The endoscopist scoring rate of $60 \%$ is most probably due to the limited administrative time in daily practice. Also, use of patient-reported questionnaires restricts medical data collection as compared to chart review. Therefore we cannot exclude the possibility of selection bias (such as previous experience with colonoscopy) in assessing secondary endpoints.

\section{Conclusion}

We conclude that implementing CAI leads to a properly cleaned colon at colonoscopy, with a positive impact on patient experience. Given the above results, this impact may be further augmented when combining the practical side of CAI with the option of a personalized nurse contact. Computer-aided representation of the patient journey through the medical landscape will require constant feedback and further research should include updates of the current CAI.

Use of a larger randomized controlled, multicenter trial design with these added elements might also show non-inferiority and cost-effectiveness of such an approach. Macroeconomic effects of less short-absence sick leave might also be interesting.

\section{Acknowledgements}

The authors would like to thank Tjeerd van der Ploeg for his statistical knowledge and support. This trial was funded by the Medical Centre of Alkmaar. Medify (software developer) had no role in the design and conduct of the study or in the writing and submission of the manuscript.

\section{Competing interests}

None

References

[1] Zauber AG, Winawer SJ, O'Brien M] et al. Colonoscopic polypectomy and long-term prevention of colorectal-cancer deaths. N Engl J Med 2012; 366: 687-696

[2] Couric K. An unexpected turn: My life as a cancer advocate. Am J Gastroenterol 2016; 111: 594 - 595

[3] Bytzer P, Lindeberg B. Impact of an information video before colonoscopy on patient satisfaction and anxiety - a randomized trial. Endoscopy 2007; 39: 710 - 714

[4] Rex DK. Optimal bowel preparation-a practical guide for clinicians. Nat Rev Gastroenterol Hepatol 2014; 11: 419-425

[5] Clark BT, Rustagi T, Laine L. What level of bowel prep quality requires early repeat colonoscopy: systematic review and meta-analysis of the impact of preparation quality on adenoma detection rate. Am J Gastroenterol 2014; 109: 1714 -1723, quiz 1724 
[6] Rex DK, Imperiale TF, Latinovich DR et al. Impact of bowel preparation on efficiency and cost of colonoscopy. Am J Gastroenterol 2002; 97: $1696-1700$

[7] Rosenfeld G, Krygier D, Enns RA et al. The impact of patient education on the quality of inpatient bowel preparation for colonoscopy. Can J Gastroenterol 2010; 24: 543 - 546

[8] Rembacken B, Hassan C, Riemann JF et al. Quality in screening colonoscopy: position statement of the European Society of Gastrointestinal Endoscopy (ESGE). Endoscopy 2012; 44: 957 - 968

[9] Calderwood AH, Lai EJ, Fix OK et al. An endoscopist-blinded, randomized, controlled trial of a simple visual aid to improve bowel preparation for screening colonoscopy. Gastrointest Endosc 2011; 73: 307 314

[10] Spiegel BM, Talley J, Shekelle P et al. Development and validation of a novel patient educational booklet to enhance colonoscopy preparation. Am J Gastroenterol 2011; 106: 875-883

[11] Tae JW, Lee JC, Hong S J et al. Impact of patient education with cartoon visual aids on the quality of bowel preparation for colonoscopy. Gastrointest Endosc 2012; 76: $804-811$

[12] Luo YY. Effects of written plus oral information vs. oral information alone on precolonoscopy anxiety. J Clin Nurs 2013; 22: 817-827

[13] Prakash SR, Verma S, McGowan J et al. Improving the quality of colonoscopy bowel preparation using an educational video. Can J Gastroenterol 2013; 27: 696 - 700

[14] Chang CW, Shih SC, Wang HY et al. Meta-analysis: The effect of patient education on bowel preparation for colonoscopy. Endosc Int Open 2015; 3: E646-E652
[15] Shaw M], Beebe T], Tomshine PA et al. A randomized, controlled trial of interactive, multimedia software for patient colonoscopy education. J Clin Gastroenterol 2001; 32: 142 - 147

[16] Kakkar A, Jacobson BC. Failure of an Internet-based health care intervention for colonoscopy preparation: a caveat for investigators. JAMA Intern Med 2013; 173: 1374-1376

[17] Lai EJ, Calderwood AH, Doros G et al. The Boston bowel preparation scale: a valid and reliable instrument for colonoscopy-oriented research. Gastrointest Endosc 2009; 69: 620-625

[18] Rostom A, Jolicoeur E. Validation of a new scale for the assessment of bowel preparation quality. Gastrointest Endosc 2004; 59: 482 - 486

[19] Fox MP. A systematic review of the literature reporting on studies that examined the impact of interactive, computer-based patient education programs. Patient Educ Couns 2009; 77: 6-13

[20] Chan AW, Tetzlaff JM, Altman DG et al. SPIRIT 2013 statement: defining standard protocol items for clinical trials. Ann Intern Med 2013; 158: $200-207$

[21] Garg S, Girotra M, Chandra L et al. Improved bowel preparation with multimedia education in a predominantly African-American population: A randomized study. Diagn Ther Endosc 2016; 2016: 2072401

[22] Wilson LJ, Yepuri JN, Moses RE. The advantages and challenges of measuring patient experience in outpatient clinical practice. Part 2: History of patient satisfaction in health care. Am J Gastroenterol 2016; 111: $587-588$ 